See Article page 34 .

\section{Commentary: Closing the "gaps," single-stage or two-stage minimally invasive hybrid maze?}

\author{
Vijay S. Patel, MD, and Richard Lee, MD, MBA
}

Current guidelines recommend invasive endocardial catheter ablation (CA) for patients with atrial fibrillation (AF) refractory to medical management; however, CA has poor long-term outcomes, particularly in the most challenging patients with persistent $\mathrm{AF}$ or patients with longstanding persistent AF. ${ }^{1}$ The Cox-maze III (CM-III) open cut-andsew surgical procedure has significantly better long-term outcomes in this challenging group of patients and is considered the gold standard of surgical ablation (SA). ${ }^{2}$ Despite numerous single-center studies reporting similar long-term outcomes, the CM-III procedure failed to gain widespread acceptance due to its highly invasive and complex technique requiring cardiopulmonary bypass. Instead, the surgical community embarked on efforts to develop alternative minimally invasive (MIS) SA techniques with and without cardiopulmonary bypass, embracing new technologies to create transmural ablation lesions replacing the cut-and-sew procedure, exceed CA outcomes with acceptable safety profile, and duplicate the CM-III outcomes. ${ }^{3-}$

The article by Zheng and colleagues ${ }^{8}$ is a feasibility study to move the needle further toward the classic CM-III anatomy-based bi-atrial lesions using an MIS beating-heart thoracoscopic SA technique combined with single-stage endocardial CA. In a cohort of 27 patients, freedom from atrial tachyarrhythmia (AT) with or without antiarrhythmic drugs after a single hybrid procedure was $64 \%$ and $60 \%$ at 12 months, respectively, and the addition

\footnotetext{
From the Division of Cardiothoracic Surgery, Department of Surgery, Augusta University, Medical College of Georgia, Augusta, Ga.

Disclosures: The authors reported no conflicts of interest.

The Journal policy requires editors and reviewers to disclose conflicts of interest and to decline handling or reviewing manuscripts for which they may have a conflict of interest. The editors and reviewers of this article have no conflicts of interest.

Received for publication Nov 21, 2020; revisions received Nov 21, 2020; accepted for publication Nov 26, 2020; available ahead of print Dec 8, 2020.

Address for reprints: Richard Lee, MD, MBA, Division of Cardiothoracic Surgery, Department of Surgery, Augusta University, Medical College of Georgia, Augusta, GA (E-mail: ricklee@augusta.edu).

JTCVS Techniques 2021;5:43-4

2666-2507

Copyright (C) 2020 The Authors. Published by Elsevier Inc. on behalf of The American Association for Thoracic Surgery. This is an open access article under the CC BY-NCND license (http://creativecommons.org/licenses/by-nc-nd/4.0/).

https://doi.org/10.1016/j.xjtc.2020.11.032
}

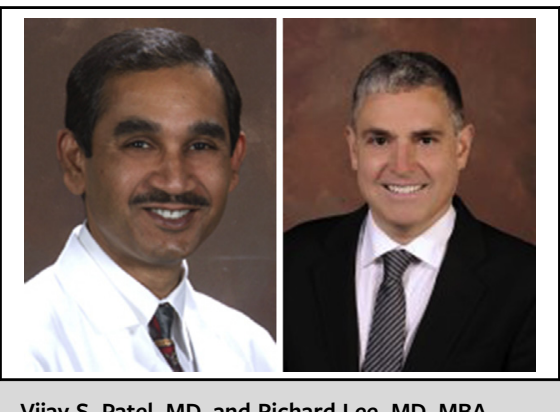

Vijay S. Patel, MD, and Richard Lee, MD, MBA

$$
\begin{aligned}
& \text { CENTRAL MESSAGE } \\
& \text { Despite improvements in tech- } \\
& \text { niques, technologies, outcomes, } \\
& \text { and safety of MIS treatment of } \\
& \text { AF, challenges persist to close } \\
& \text { the "gaps" and gain widespread } \\
& \text { acceptance among the surgical } \\
& \text { community. }
\end{aligned}
$$

of a redo CA increased the freedom from atrial tachyarrhythmia to $77.8 \%$ and $74.1 \%$ at 12 months, respectively. The left and right atrial size decreased in patients maintaining sinus rhythm. The hybrid concept is not unique, although the bi-atrial surgical technique is an improvement to previously reported primarily left atrial thoracoscopic SA albeit with variable additional lesions interspersed between studies. Their outcomes are acceptable but lack significant improvement to outcomes reported in the literature by numerous other centers. ${ }^{9}$ The safety profile is admirable compared with other reports. The authors acknowledge the important limitations of their preliminary experience, including a small sample size with short follow-up preventing over-reaching conclusions of efficacy, challenges in their technique to achieve reliable mitral isthmus lesions, abandoned right atrium endocardial ablation in most patients, and the unreliability of assuring transmural linear lesions with the bipolar unidirectional radiofrequency device. A concomitant single-step hybrid CA procedure is obligatory, given the premise of this study; however, a 2-staged hybrid approach may avoid unnecessary CA procedure in some patients, reliably address pulmonary vein reconnection, and perform staged additional ablation lesions for failed index MIS thoracoscopic SA as noted by Lee and colleagues. ${ }^{10}$ The authors' inability to approximate the CM-III ablation lesions and desired outcome is not unique to this study, given the technical challenges associated with an MIS 
beating-heart thoracoscopic ablation with or without complementary hybrid CA, the currently available alternative ablation technology to assure transmural lesions, the paucity of data on mechanisms of ablation failure to refine procedural techniques, heterogeneous hybrid ablation protocols in reported studies, absence of convincing literature to support single-step versus 2 -stage hybrid approach, incomplete understanding of the pathogenesis of $\mathrm{AF}$, and lack of convincing randomized controlled trials. Perhaps, their contribution will rekindle future studies among the surgical community to embrace a bi-atrial ablation protocol also proposed by Cox and colleagues $^{11}$ in their template for the "hybrid Cox-mazeIV" procedure for longstanding persistent AF.

\section{References}

1. Pak HN. Catheter ablation of long-standing persistent atrial fibrillation: a reckless challenge or a way to real cure? Korean Circ J. 2019;49:134-45.

2. Prasad SM, Maniar HS, Camillo CJ, Schuessler RB, Boineau JP, Sundt TM III, et al. The Cox maze III procedure for atrial fibrillation: long-term efficacy in patients undergoing lone versus concomitant procedures. J Thorac Cardiovasc Surg. 2003;126:1822-8.
3. Harky A, Bithas C, Chan JSK, Snosi M, Pousios D, Muir AD. Surgical treatment of atrial fibrillation: cutting through the edges. Braz J Cardiovasc Surg. 2020;35: 375-86.

4. Ruaengsri C, Schill MR, Khiabani AJ, Schuessler RB, Melby SJ, Damiano RJ Jr. The Cox-maze IV procedure in its second decade: still the gold standard? Eur J Cardiothorac Surg. 2018;53(suppl_1):i19-25.

5. Ad N, Holmes SD, Friehling T. Minimally invasive stand-alone Cox maze procedure for persistent and long-standing persistent atrial fibrillation: perioperative safety and 5-year outcomes. Circ Arrhythm Electrophysiol. 2017; 10:e005352.

6. Sirak JH, Schwartzman D. Interim results of the 5-box thoracoscopic maze procedure [Erratum in: Ann Thorac Surg. 2013;95:1140]. Ann Thorac Surg. 2012;94:1880-4.

7. Maesen B, Pison L, Vroomen M, Luermans JG, Vernooy K, Maessen JG, et al. Three-year follow-up of hybrid ablation for atrial fibrillation. Eur $J$ Cardiothorac. 2018;53:126-32.

8. Zheng Z, Yao Y, Li H, Zheng L, Liu S, Lin H, et al. Simultaneous hybrid maze procedure for long-standing persistent atrial fibrillation with dilated atrium. $J$ Thorac Cardiovasc Surg Tech. 2021;5:34-42.

9. Khoynezhad A, Ellenbogen KA, Al-Atassi T, Wang PJ, Kasirajan V, Wang X, et al. Hybrid atrial fibrillation ablation: current status and a look ahead. Circ Arrhythm Electrophysiol. 2017;10:e005263.

10. Lee R, McCarthy PM, Passman RS, Kruse J, Malaisrie SC, McGee EC, et al. Surgical treatment for isolated atrial fibrillation minimally invasive vs classic cut and sew maze. Innovations (Phila). 2011;6:373-7.

11. Cox JL, Churyla A, Malaisrie SC, Pham DT, Kruse J, Kislitsina ON, et al. A Hybrid maze procedure for long-standing persistent atrial fibrillation. Ann Thorac Surg. 2019;107:610-8. 